\title{
Syndrome de la veine cave supérieure
}

\section{Superior vena cava syndrom}

\section{S. Gennai · C. Bernardet}

Reçu le 10 octobre 2012 ; accepté le 6 novembre 2012

(C) SFMU et Springer-Verlag France 2012

Voici la photographie d'une patiente de 85 ans présentant un syndrome de la veine cave supérieure, associé à une embolie pulmonaire bilatérale. Les symptômes d'admission apparus en quelques jours étaient : un œdème de la face, du cou, de la partie supérieure du thorax (œdème en pèlerine) et des membres supérieurs, une cyanose, le développement d'une circulation veineuse collatérale, des céphalées faisant suspecter un œdème cérébral et une dyspnée (Figs 1,2).

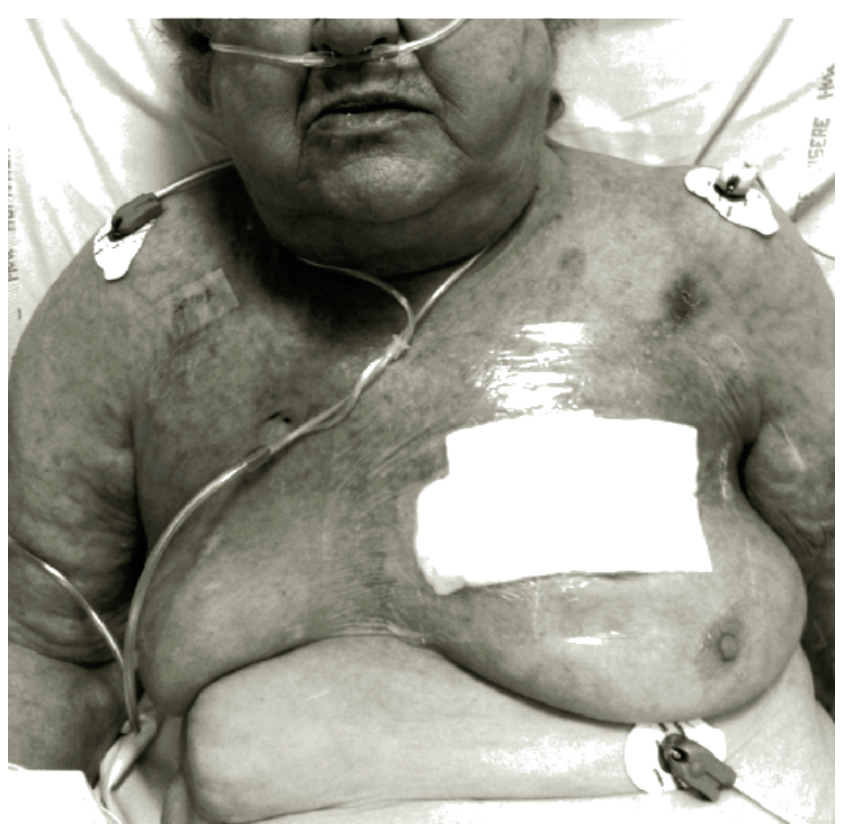

Fig. 1 Aspect sémiologique typique du syndrome de la veine cave supérieure

\section{Référence}

1. Molhem A, Sabry A, Bawadekji H, Al Saran K (2011) Superior vena cava syndrome in hemodialysis patient. Saudi J Kidney Dis Transpl 22:381-6

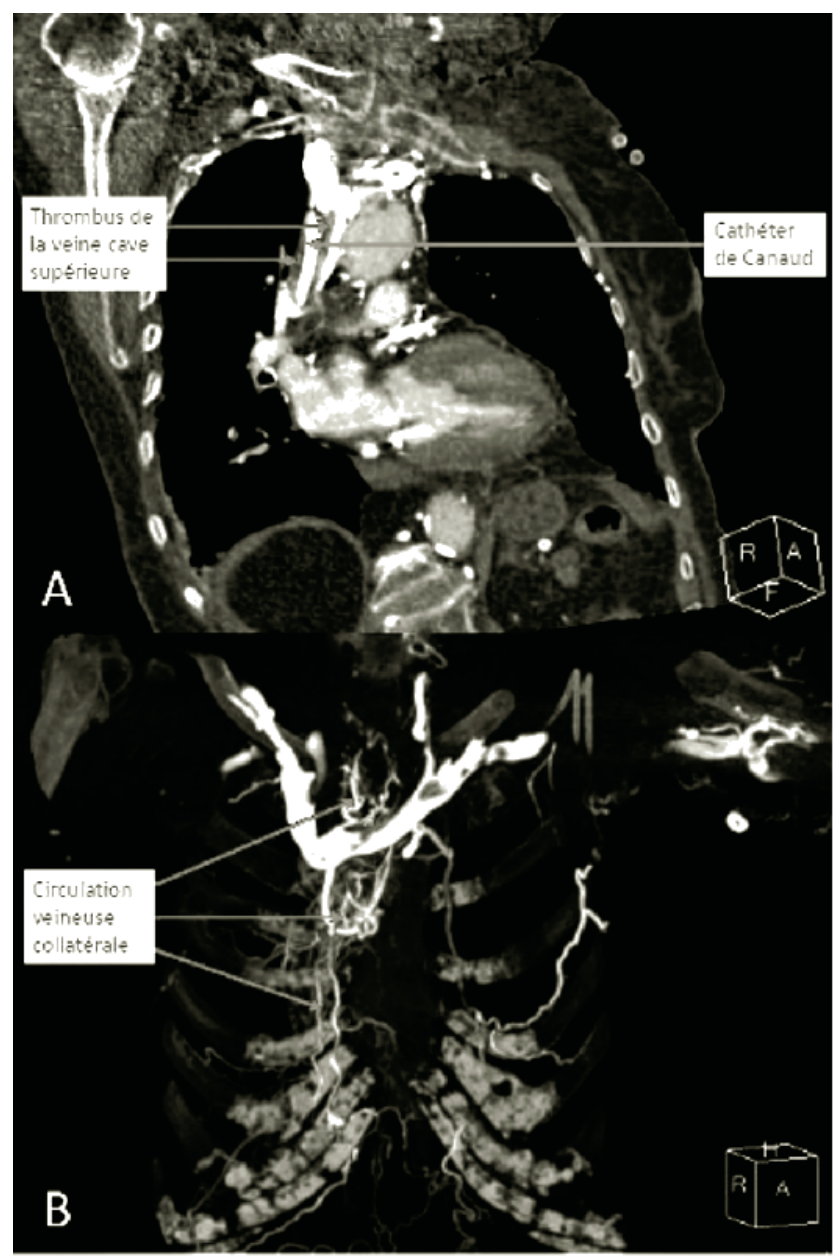

Fig. 2 Reconstructions scannographiques 3D

A : thrombose de la veine cave supérieure, centrée sur un cathéter de Canaud (cathéter de dialyse)

B : développement d'une circulation veineuse collatérale 